\title{
POLÍTICAS DE FORMAÇÃO E TRABALHO DOCENTE NA CONTEMPORANEIDADE: UMA DISCUSSÃO A PARTIR DO CONCEITO GRAMSCIANO DE INTELECTUAL ORGÂNICO
}

\author{
POLICIES FOR TEACHER TRAINING AND WORK IN THE CONTEMPORARY WORLD: A \\ DISCUSSION BASED ON THE GRAMSCIAN CONCEPT OF ORGANIC INTELLECTUAL
} POLÍTICAS DE FORMACIÓN Y TRABAJO DOCENTE EN LA CONTEMPORANEIDAD: UNA DISCUSIÓN DESDE EL CONCEPTO GRAMSCIANO DE INTELECTUAL ORGÁNICO

Hildegard Susana Jung ${ }^{1}$

Maria de Lourdes Pinto de Almeida²

${ }^{1}$ Doutoranda em Educação pelo Centro Universitário La Salle (UNILASALLE) - Canoas - RS - Brasil. ${ }^{2}$ Doutora em Educação pela UNICAMP. Docente do Programa de Pós-Graduação em Educação da Universidade do Oeste de Santa Catarina (UNOESC) - Joaçaba - SC - Brasil.

Resumo: Este artigo sobre as políticas de formação e a profissão docente traz uma revisão da literatura a respeito do tema, com destaque para as exigências que se impõem a estes profissionais na prática pedagógica escolar contemporânea. De cunho teórico, o objetivo é levantar um debate sobre as exigências que a contemporaneidade demanda do docente e sobre a necessidade de formação e de profissionalização da sua prática. A tarefa de formar professores para atuar na escola da sociedade do século XXI tem se mostrado complexa, mas o legado da teoria gramsciana contribui para que se coloquem estes valores em xeque, especialmente quando se estudam os conceitos de intelectual orgânico. Com este debate espera-se que as políticas de formação sejam analisadas, não somente visando à teoria que o Estado dissemina sobre, mas sim em uma perspectiva histórico-crítica, mostrando as contradições vigentes em uma tentativa de resgatar a identidade do professorado e sua profissionalidade, melhorando assim a qualidade da educação, para além do mercado.

Palavras-chave: Políticas de formação inicial; Formação e Trabalho docente; Intelectual orgânico.

\begin{abstract}
This article on teacher training policies and the teaching profession brings a review of the literature on the subject, highlighting the requirements that are imposed on these professionals in the contemporary pedagogical practice in schools. Theoretical in nature, the objective of this study is to promote debate on the demands that contemporaneity places on the teacher, and the need for training and professionalization of their practice. The task of educating teachers to work in the school of 21st century society is complex, but the legacy of Gramscian theory has contributed to putting these values in check, especially when we study the concepts of organic intellect. With this debate, it is hoped that education policies will be analyzed, not only in terms of the theory that the State disseminates, but rather, from a historical-critical perspective, showing the contradictions at work, in an attempt to promote the identity of the professorship and its professionalism, and thereby improve the quality of education, beyond the market.
\end{abstract}

Keywords: Initial training policies; Teacher Training and Teaching; Organic Intellect.

Resumen: Este artículo sobre las políticas de formación y la profesión docente trae una revisión de la literatura respecto al tema, con destaque para las exigencias que se imponen a estos profesionales 
en la práctica pedagógica escolar contemporánea. De cuño teórico, el objetivo es levantar un debate sobre las exigencias que la demanda la contemporaneidad del docente y sobre la necesidad de formación y de profesionalización de su práctica. La tarea de formar profesores para actuar en la escuela de la sociedad del siglo XXI se ha mostrado compleja, pero el legado de la teoría gramsciana contribuye para que coloquemos estos valores en jaque, especialmente cuando estudiamos los conceptos de intelectual orgánico. Con este debate se espera que las políticas de formación sean analizadas, no sólo visando la teoría que el Estado disemina sobre, sino en una perspectiva históricocrítica, mostrando las contradicciones vigentes en un intento de rescatar la identidad del profesorado y su profesionalidad, mejorando así la calidad de la educación, hacia más allá del mercado.

Palabras-clave: Políticas de formación inicial; Formación y Trabajo docente; Intelectual orgánico.

\section{Primeiras palaVRas}

“... os próprios pesquisadores científicos, estes burgueses da ciência, estes honestos contribuintes para a construção da verdade, parecem (...) sentir cada vez mais vivamente a contradição entre o que eles fazem e o que eles são, veem-se divididos entre seu humanismo social e seu cientificismo profissional. Descobrem uma alienação científica às avessas que não é a alienação do homo vulgaris (homem comum) em face do mago da informática, mas, ao contrário, é a alienação do homo scientificus face ao mundo humano que ele contribuiu, se não para destrui-lo pelo menos para mudá-lo, de tal modo que o que ele próprio é encontra-se posto em questão". (MOLES, 1996, p. 101).

O estudo a respeito da formação inicial e continuada docente tem sido alvo de muitas investigações acadêmicas nas últimas décadas. Diversos autores têm se dedicado a estudar o assunto, dentre os quais, para citar somente alguns, podemos referir: Nóvoa (2009), Alarcão (1996) e Roldão (1999) em Portugal; Schön (2000), Zeichner (1993), Popkewitz (1992) e Giroux (1997) nos Estados Unidos; Gimeno Sacristán (1988), Gil Pérez (1993), Imbernón (2001) na Espanha; Lessard (2005) no Canadá, Paulo Freire (1992) no Brasil, entre outros.

A partir dos anos de 1990, termos como "treinamento, capacitação e reciclagem, que denotavam a ideia de aprendizado, de forma vertical e acumulativa, de determinadas técnicas ou adequações às novas incumbências e inovações tecnológicas" (ROCHA, 2010, p. 11) foram incorporados à ideia de formação docente, denotando grande aproximação ao vocabulário utilizado nas empresas.

A Lei de Diretrizes e Bases - LDB (BRASIL, 1996) apresenta os termos "capacitação em serviço" (Art. 61, inciso I; Art. 87, inciso III), "educação continuada" (Art. 63, inciso III; Art. 80, caput) e "aperfeiçoamento profissional continuado" (Art. 67, inciso II). O Plano Nacional de Educação (PNE-2014-2024) sugere a terminologia "formação continuada", "programas contínuos de formação sistemática", "formação permanente" e "formação em serviço". O Plano de Desenvolvimento da Educação (PDE - 2007) aplica o termo "formação continuada". Recentemente, a Resolução n. 2, de $1^{\circ}$ de julho de 2015, do Conselho Nacional de Educação, via Ministério da Educação, e em consonância com a LDB, dispõe, em seu art. $1^{\circ}, \S 1^{\circ}$, que as universidades ou outras entidades de formação deverão, de forma articulada e colaborativa com os sistemas de ensino, promover "a formação inicial e continuada dos profissionais do magistério para viabilizar o atendimento às suas especificidades nas diferentes etapas e modalidades de educação básica, observando as normas específicas definidas pelo Conselho Nacional de Educação (CNE)" (BRASIL, 2015, p. 3). 
O termo "formação continuada" é descrito por Imbernón (2001) como um processo autorreflexivo, no qual o educador (re)avalia permanentemente seu fazer pedagógico à luz da teoria, concebendo-o como aquele cuja base será a reflexão dos sujeitos sobre sua prática docente. Deste modo, uma política de formação inicial docente, para alcançar verdadeiramente seus objetivos, deve permitir que os educadores examinem suas teorias implícitas, seus esquemas de ação, suas atitudes, etc., realizando um processo constante de autoavaliação que oriente seu trabalho.

A tarefa de formar professores para atuar na escola da sociedade contemporânea tem se mostrado complexa, mas o legado de Antônio Gramsci pode contribuir neste sentido. Conceitos como o de intelectual orgânico permanecem muito úteis. O intelectual orgânico trabalha cooperativamente e, em sintonia com a comunidade, aperfeiçoa-se de modo a promover o desenvolvimento de seus alunos como seres humanos, numa escola que consegue "articular a formação do professor com a humanista, contrária à divisão da escola burguesa em escolas técnicas para os pobres e de cultura humanista para os ricos" (TORRES, 2012, p. 48).

Para dar conta dos objetivos de nossa pesquisa, esperando que o debate contribua para o resgate da identidade do professorado e sua profissionalidade, melhorando assim a qualidade da educação, primeiramente traçamos um breve histórico das políticas de formação. Na sequência, refletimos sobre as exigências que a contemporaneidade demanda do professor no século XXI e a necessidade de profissionalização da prática docente, tendo a teoria gramsciana como pano de fundo para as reflexões. O debate trilhará por questões como: a partir do panorama atual das políticas de formação de professores, quais são as exigências que demandam deste profissional a prática pedagógica escolar? Qual é a contribuição de Gramsci para a realidade escolar que encontramos? Como está a formação do professor na atualidade?

Quanto à metodologia utilizada, trata-se de um estudo de cunho teórico, o qual realiza uma revisão da literatura, incluindo documentos legais. Seguindo a linha filosófica dialética, reflete crítica e autocriticamente, mas entende também que o mundo se apresenta em sua 'pseudoconcreticidade' (KOSIK, 1976). O posicionamento epistemológico é o neo-marxismo, com fundamentação em Gramsci, posto que este é um marxista com uma dialética voltada à educação somente, enquanto que a dialética marxista hegeliana em seus movimentos de tese, antítese, síntese, se dirige a temas universais. Como linha epistemológica, adotamos a concepção histórico-crítica, buscando compreender a educação no contexto da sociedade, considerando o importante papel político que compreende o ambiente escolar. "A compreensão histórico-crítica surge no quadro das tendências críticas da educação brasileira, objetivando a superação das teorias crítico-reprodutivistas" (DOZOL, 1994, p. 116). Neste sentido, Libâneo (1986, p. 8) explica que esta concepção "pretende que o domínio de instrumentos culturais e científicos consubstanciados no saber elaborado auxilie no conhecimento e compreensão das realidades sociais". Desta forma, não consideramos a exclusão da análise dos elementos conjunturais, ao contrário, buscamos um entendimento real e não somente literal dos achados. 


\title{
Políticas de FORMAÇÃo doCENTE NO BRASIL: UM BREVE HiStóRICO
}

\begin{abstract}
"Enquanto prevalecer na política educacional a orientação de caráter neoliberal, a estratégia da resistência ativa será a nossa arma de luta. Com ela nos empenharemos em construir uma nova relação hegemônica que viabilize as transformações indispensáveis para adequar a educação às necessidades $e$ aspirações da população brasileira". (SAVIANI, 1997, p. 238).
\end{abstract}

A partir dos anos 1990, segundo Frigotto (1995), se estabelece no Brasil uma nova base técnico-científica (microbiologia, microeletrônica e novas fontes de energia) para a reestruturação produtiva do capitalismo, fato que culminou em mudanças políticas, econômicas e culturais em âmbito mundial. As reformas educacionais estão neste 'bojo' de "reordenamento das relações societárias global/local; Estado/sociedade" (ROCHA, 2010, p. 29). Neste sentido, Dourado (2001, p. 49) explica que a escola se torna um elo entre a socialização dos conhecimentos "técnico-científicos historicamente produzidos pelo desenvolvimento de habilidades, capacidades e competências sociais requeridas, predominantemente, em sintonia com o poder produtivo".

Internacionalmente, em 1996, surge o Relatório para a Unesco da Comissão Internacional sobre a Educação para o Século XXI, com o título "Educação, um tesouro a descobrir", tendo como protagonista o francês Jacques Delors. O documento traz conceitos orientadores à educação, como a ideia de educação permanente e os quatro pilares da educação: aprender a viver juntos, aprender a conhecer, aprender a fazer e aprender a ser. Este texto apresenta $o$ discurso do Estado Liberal, conservador e o que este pretende com a formação de professores. O discurso vai ao encontro do mercado capitalista e da formação profissional onde a técnica se sobrepõe à razão, numa perspectiva contrária a tudo o que já se pregou sobre pedagogia histórico-crítica e plural da década de 1970 do século XX.

De acordo com Saviani (2008), a proposta de Delors baseia-se no pragmatismo de Dewey e nos preceitos da Escola Nova (1932), que coloca como ponto de partida do ensino a necessidade do aluno, amparando-se em métodos práticos. Desta maneira, assim como o pensamento da Escola Nova esbarrou na falta de recursos materiais para o desenvolvimento das experiências práticas, assim o problema se repete com os Pilares da Educação, já que as escolas se apresentam cada vez mais sucateadas de bibliotecas, laboratórios e outros recursos. Assim, da maneira como se apresenta, Duarte (2001) alerta que o "aprender a aprender", baseado em uma interpretação da concepção de Vygotsky, não atende aos estudantes da classe trabalhadora por sua ausência de compromisso político e ideológico. Sobre este assunto, Saviani (2008) esclarece que, para uma proposta educativa alcançar os filhos da classe trabalhadora, ela precisa gerar transformação social, considerando os conteúdos a partir de sua totalidade e, a partir de então, o aluno poderá apropriar-se do conhecimento produzido socialmente como significativo para sua vida. Os Pilares da Educação, de acordo com Saviani (2011) e Duarte (2001), da forma como se apresentam, sem uma política de fortalecimento dos espaços físicos e recursos, têm como intenção a manutenção do atual processo de dominação da classe burguesa, na medida em que sugerem a convivência com as diferenças e os saberes díspares, desmobilizando qualquer possibilidade de transformação social. Em outras palavras: 
trabalham para que tudo seja aceito da forma como se apresenta nos países periféricos: uma sociedade com gritantes diferenças sociais, exacerbado individualismo, exclusão social e exploração da mão de obra barata. Com os princípios de Delors, almejamos um convívio pacífico em que:

\footnotetext{
Por um lado, procura-se dar aos explorados e excluídos o suficiente para que sua condição concreta de vida não se torne generalizadamente insuportável e, por outro, busca-se difundir uma mentalidade de convivência pacífica, por meio da qual as desigualdades seriam identificadas com as diferenças, no intuito de enfraquecer qualquer clamor por uma sociedade menos injusta e desigual. (DUARTE, 2001, p. 74).
}

Outro problema identificado por Saviani (2008) no pragmatismo é que, ao centrar o conhecimento nas necessidades do aluno somente, esse acaba satisfazendo as problemáticas cotidianas sem aprofundamento e, portanto, esvaziando o conhecimento. Esta metodologia caminha para o lado oposto daquilo que Gramsci (1974) supunha como papel do intelectual orgânico, que é desenvolver a consciência crítica dos alunos e a capacidade de questionar a realidade que se apresenta.

Nesse contexto, a escola passa a ser o principal instrumento nas decorrentes reformas educacionais na América Latina, que no Brasil têm fundamento legal na LDB (1996), principalmente em seu Artigo 121, estabelecendo as incumbências da escola, com notório acento descentralizador e de pretensa autonomia às instituições de ensino. $E$ isto não é por acaso, já que os preceitos da política neoliberal caminham na direção do Estado mínimo, ou seja, uma redução das atribuições da União, que passa a assumir uma postura reguladora, chamado também de estado-avaliador (ALMEIDA, 2002) ou Pátria Panóptica (JUNG; SUDBRACK, 2016).

$\mathrm{Na}$ contramão das reformas educacionais sugeridas pelos organismos internacionais (Tailândia, 1999; Dakar, 2000; Coreia, 2015, principalmente) que colocam os professores como agentes fundamentais na melhoria da qualidade de ensino, estão órgãos como a Associação Nacional de Pós-Graduação e Pesquisa em Educação (Anped), Associação Nacional de Política e Administração da Educação (Anpae) e Associação Nacional pela Formação dos Profissionais da Educação (Anfope), que requerem uma articulação entre condições de trabalho e valorização salarial com formação inicial e continuada.

Nesse período (meados dos anos de 1990 e 2000), o MEC adotou diversas estratégias com foco nos eixos avaliação, currículo e gestão, dentre as quais citamos: Programa Dinheiro Direto na Escola; políticas de avaliação como o Sistema de Avaliação da Educação Básica (SAEB); Exame Nacional do Ensino Médio (ENEM) e Exame Nacional de Cursos; TV Escola; distribuição do Guia de Avaliação do Livro Didático; discussão e implementação dos Referenciais Curriculares para a Educação Básica (Parâmetros Curriculares Nacionais - PCN e Referenciais Curriculares Nacionais); e, mais recentemente, a discussão em torno da Base Nacional Comum Curricular (BNCC) e a Lei 13.415, de 16 de fevereiro de 2017, conhecida como lei da reforma do Ensino Médio.

Entretanto, as tradicionais formações iniciais de professores "voltadas à preparação individual para o trabalho se têm revelado ineficazes" (GATTI; BARRETO; ANDRÉ, 2011), pois a dissociação entre a teoria e as experiências docentes não mais atendem aos desafios da contemporaneidade. Além disso, nos últimos anos, principalmente devido às recentes políticas 
de ajuste fiscal, as políticas de formação têm sofrido profundos cortes. "O corte de verbas atinge toda a área de Educação, reflexo das crises financeira e política que acometem o país" (KESLEY, 2015, n.p.).

De acordo com Saviani (2009), não é possível que, numa sociedade classificada como "sociedade do conhecimento" e, cientes da importância da educação - e, por consequência, da formação de professores -, as políticas públicas estejam dia após dia buscando a redução de custos. É necessário, segundo o autor, delegar à educação sua devida importância - e recursos compatíveis com essa importância -, de maneira a:

\footnotetext{
... eleger a educação como máxima prioridade, definindo-a como o eixo de um projeto de desenvolvimento nacional e, em consequência, carrear para ela todos os recursos disponíveis. Assim procedendo, estaríamos atacando de frente, e simultaneamente, outros problemas do país, como saúde, segurança, desemprego, pobreza, infraestrutura de transporte, de energia, abastecimento, meio ambiente etc. Infelizmente, porém, as tendências que vêm predominando na educação brasileira caminham na contramão dessa proposta. (SAVIANI, 2009, p. 153).
}

Muito antes de ser uma proposta romântica, diz o autor, é uma proposta para colocar o país em sua máxima capacidade produtiva, já que a educação é a base de todas as outras atividades.

\section{Trabalho docente no século XXI: entre a ÉticA e o MERCAdo - A CONTRIBUIÇÃO DA TEORIA GRAMSCIANA}

No viés das mudanças da sociedade contemporânea queantes referimos com Gatti, Barreto e André (2011), as autoras constatam que, além dos tensionamentos resultantes dos valores e dos comportamentos, os jovens estudantes, considerando seu estágio de desenvolvimento, facilmente deixam-se influenciar por certos modismos, estranhos aos professores, gerando instabilidade. Desta forma, "cada vez mais, os professores trabalham em uma situação em que a distância entre a idealização da profissão e a realidade do trabalho tende a aumentar" (BARRETO; ANDRÉ, 2011, p. 25), considerando a complexidade do contexto no qual a escola está inserida. Ante esta nova situação, um novo perfil docente se faz necessário.

Com relação ao exposto, em estudo realizado sobre o ser e o estar na profissão, Abdalla (2001, p. 15) constatou que "a maior parte de nós nos sentimos impotentes, ansiosos e inseguros a respeito do trabalho docente, especialmente face às mudanças culturais e sociais". Nesta investigação, a autora auferiu que as representações dos professores participantes da pesquisa enfatizaram dois aspectos principais: a necessidade da formação e do desenvolvimento profissional, e a importância da escola como principal lugar de sua profissionalização. Ainda neste sentido, é necessário e "possível gerar um novo habitus" (ABDALLA, 2001, p. 16). Esta nova postura está ligada a uma profissionalidade que se articula com um espaço no qual são socializadas maneiras de pensar, de decidir e de avaliar os atos e as atenções, exigindo, além dos saberes, competências que possibilitem a mobilização.

Uma proposta de socialização formativa para os docentes são as sessões formativas propostas por Picado (2009, p. 24), as quais, além de se apresentarem como uma oportunidade de aprendizagem contínua, servem também para o fortalecimento da saúde mental do educador, 
pois organizadas sequencialmente podem "despertar os docentes para mobilizar conexões e sinergias". Por meio desta estratégia, o autor insere um novo estudo ao cenário da docência: o do bem-estar docente, o qual define como "a motivação e a realização do professor em virtude de um conjunto de competências de resiliência e de estratégias desenvolvidas para conseguir fazer face às exigências e dificuldades profissionais, ultrapassando-as e melhorando o seu desempenho" (PICADO, 2009, p. 4). Ainda segundo o autor, há uma relação direta entre o bemestar docente e o bem-estar discente, pois, "tendo em conta os fenômenos de modelação, o professor motivado e realizado tem uma maior probabilidade de ter alunos que também se caracterizam dessa forma" (PICADO, 2009, p. 4).

No mundo contemporâneo, novas exigências permeiam o trabalho docente, como consideram Gatti, Barreto e André (2011, p. 25), já que o contexto social tem se modificado, assim como o perfil dos alunos:

Considerando as novas condições de permeabilidade social das mídias e da informática, dos meios de comunicação e das redes de relações - presenciais ou virtuais -, das novas posturas na moralidade e nas relações interpessoais, nas famílias e nos grupos de referência, impactos na socialização das pessoas são visíveis. As crianças ingressam nas escolas com vivências cotidianas e aprendizagens sociais prévias ou paralelas heterogêneas, com expectativas bem diferenciadas de como ocorria décadas atrás.

Ainda neste sentido, as autoras referem que uma constante contradição entre os valores e os comportamentos da comunidade, da escola e aqueles veiculados pela mídia tensionam entre si. Esta situação requer uma nova profissionalidade docente.

Referindo-se a esta profissionalidade do professorado, Bolívar (2003, p. 16) nos ensina que os anos 1980 foram marcados por uma forte valorização da gestão (o que no Brasil coincide com a adesão à política neoliberal, por recomendação de organismos multilaterais) e as práticas pedagógicas acabaram saindo do foco das discussões, mas:

Si el centro como organización se constituyó en los ochenta como unidad básica de cambio, dejando el trabajo en el aula en un segundo plano, dependiente del trabajo conjunto, en una cierta vuelta, ahora - tras la evaluación de las propuestas reestructuradoras- se vuelve a hablar de la necesaria recuperación del aula y de los procesos de enseñanza y aprendizaje.

Na contramão da preparação individual baseada nas técnicas de gestão e de linguagem empresariais como antes referimos, as propostas de aprendizagem e formação em redes (DEVÉS, 2003), trabalho colaborativo (DAMIANI et al., 2009); sessões formativas (PICADO, 2009) e comunidades de prática (NÓVOA, 2009; SCHÖN, 1992), apresentamse como uma forma de resgatar a identidade do professorado e sua profissionalidade (BOLÍVAR, 2003), e melhorar a qualidade da educação. As novas tecnologias podem ser um aliado importante, segundo Damiani et al. (2009), no sentido de que a escola reveja suas concepções e consiga adaptar-se ao mundo líquido contemporâneo (BAUMAN, 2001), uma vez que precisa compreender - e com ela os professores e os gestores - que não é mais o "lócus privilegiado do saber instituído" (DAMIANI et al., 2009, p. 25). Neste viés, a autora refere os fatores que podem influenciar fortemente esta prática: a qualidade das trocas que ocorrem e o ambiente no qual acontecem, que deverá ser propício, estimulando o diálogo e a participação de todos. Como princípios sobre os quais deverá assentar-se o trabalho colaborativo, esclarece: 
Crescimento e respeito mútuo entre os participantes do grupo; valorização dos indivíduos como profissionais e pessoas; socialização de saberes aprendidos pelas experiências e dificuldades; atenção para o processo de estudo e investigação de problemas para a tomada de decisões individuais e/ou coletivas.

(DAMIANI et al., 2009, p. 9).

As comunidades de prática (SCHÖN, 1992; NÓVOA, 2009) são também aliados importantes no processo de trabalho colaborativo. Nóvoa (2009, p. 13-14) observou atentamente a comunidade médica e de lá trouxe importantes lições, as quais podem ser transplantadas à formação docente:

Do que pude observar, quero chamar a atenção para quatro aspectos: i) o modo como a formação se realiza a partir da observação, do estudo e da análise de cada caso; ii) a identificação de aspectos a necessitarem de aprofundamentos teóricos, designadamente quanto à possibilidade de distintas abordagens de uma mesma situação; iii) a existência de uma reflexão conjunta, sem confundir os papéis de cada um (chefe da equipa, médicos, internos, estagiários, etc.), mas procurando mobilizar um conhecimento pertinente; iv) a preocupação com questões relacionadas com o funcionamento dos serviços hospitalares e a necessidade de introduzir melhorias de diversa ordem.

Seria desejável se os professores recém-formados pudessem contar com uma espécie de "tutor" que os acompanhasse e aconselhasse nas primeiras turmas, buscando por meio do trabalho prático soluções para o insucesso e o aprofundamento teórico para o aprendiz. É o que Nóvoa (2009, p. 15) chama de passar a formação de professores para dentro da profissão: "Nestes anos em que transitamos de aluno para professor é fundamental consolidar as bases de uma formação que tenha como referência lógicas de acompanhamento, de formação-emsituação, de análise da prática e de integração na cultura profissional docente". Em lugar desse acompanhamento, o que nossa experiência mostra é justamente o contrário: ao professor recém-formado são destinadas as turmas mais difíceis e, como o trabalho colaborativo é praticamente inexistente, este permanece abandonado à própria sorte. Devido a isso,

É urgente reforçar as comunidades de prática, isto é, um espaço conceptual construído por grupos de educadores comprometidos com a pesquisa e a inovação, no qual se discutem ideias sobre o ensino e aprendizagem e se elaboram perspectivas comuns sobre os desafios da formação pessoal, profissional e cívica dos alunos. (NÓVOA, 2009, p. 17).

Neste cenário, consideramos que o legado gramsciano tem uma importante contribuição a oferecer, seja no sentido da prática colaborativa, seja no fazer pedagógico e, inclusive, na própria profissionalidade docente. A autonomia dos intelectuais orgânicos frente às classes que eles representam eleva-os acima do estágio econômico-corporativo. Ao se desprenderem da classe dominante, os intelectuais orgânicos unem-se mais intimamente a ela para constituírem uma verdadeira superestrutura, "e não apenas um elemento inorgânico e indistinto da estrutura-corporação" (GRAMSCI, 1991, p. 424). A relação do intelectual com o mundo se dá num processo pelo qual os momentos se articulam, numa relação mediatizada e graduada. "A relação entre os intelectuais e o mundo da produção não é imediata, como é o caso nos grupos sociais fundamentais, mas é sim 'mediatizada', em diversos graus, por todo o contexto social, pelo conjunto das superestruturas, do qual os intelectuais são precisamente os funcionários". (GRAMSCI, 1995a, p. 10).

O intelectual orgânico de Gramsci atua contra-hegemonicamente, operando na sociedade civil de maneira pedagógica, posto que no pensamento gramsciano a relação 
pedagógica não se limita ao espaço e às relações escolares. Desta forma, podemos aprender com o legado gramsciano que os intelectuais orgânicos são "sujeitos políticos coletivos que expressam a auto-organização popular" (LIÁO JUNIOR, 2013, p. 189), podendo ser capazes de resistir contra-hegemonicamente ao sistema mercadológico que inunda a educação.

De acordo com Moraes e Flores (2009), para Gramsci todos os homens são intelectuais. Se isto é verdadeiro, então todos poderão, independentemente de sua posição social, desenvolver consciência histórica e, a partir dela, começar um processo de elaboração crítica. Nesta atuação, se quando nos referimos principalmente aos profissionais docentes, para a "tarefa de conceber essa visão de mundo, é imprescindível a atividade de intelectuais organicamente vinculados às transformações de seu tempo" (MISOCZKY; MORAES; FLORES, 2009, p. 459). Neste sentido, consideramos que as políticas de formação são terreno fértil para o fortalecimento das características do intelectual orgânico.

O docente inspirado pelo legado gramsciano poderá assumir características como: a) oferecer resistência à visão hegemônica e gerencial de educação; b) aliar-se à comunidade, num movimento de organização popular, para resistir hegemonicamente ao domínio do mercado sobre a educação; c) articular sua formação à concepção humanista, como um novo paradigma para a educação, tendo em vista que todo o discurso em prol de uma educação de qualidade perpassa pela vontade da promoção do desenvolvimento humano (LÜCK, 2011).

O papel do intelectual se torna fundamental frente aos novos desafios da ciência, que se traduzem, sobretudo, na tendência de o saber se tornar mera mercadoria ou na possibilidade de tornar-se um fator estratégico para se promover o bem comum. O pensamento de Antonio Gramsci tem se revelado um prisma eficaz para se compreender a atividade intelectual. As ideias desse pensador permitem explicitar aspectos da relação entre ciência e sociedade, a partir da perspectiva do desequilíbrio entre interesses sociais contrapostos. Gramsci fornece um quadro crítico ou um crivo para uma análise da atividade intelectual em sua correlação com as forças econômicas, os interesses de classes, possibilitando correlacionar aspectos empresarias, acadêmicos e políticos da criação científica-tecnológica.

A questão posta no texto Os Intelectuais e a Organização da Cultura interroga se os intelectuais constituem um grupo social autônomo e independente, ou "se cada grupo social possui sua própria categoria especializada de intelectuais continua pertinente" (GRAMSCI, 1995a, p. 03). A classe dominante economicamente, ainda que controle os aparelhos ideológicos em que se maquina o consenso necessita do uso do constrangimento como suporte para garantir a opressão, sem a qual não consegue manter a exploração. Para Gramsci, as lutas sociais e políticas nas sociedades atuais se dão menos contra o Estado do que no Estado. Este se apresenta como instância mediadora de interesses de classes, em vez de um mero representante da classe dominante. Nele, portanto, os antagonismos se manifestam. O papel do intelectual orgânico é o de organizar, conduzir e persuadir as massas, produzindo consensos. Ao ampliar o Estado ele amplia, também, o papel do intelectual.

A noção de intelectual orgânico criada por Gramsci diz respeito à atividade de integração da estrutura e superestrutura, dando a elas um vínculo orgânico. Tais intelectuais não constituem 
uma classe, mas se vinculam a determinadas classes que, ao surgirem como dominantes, já produzem seus intelectuais, como sua autoconsciência cultural e autocrítica:

Cada grupo social, nascendo no terreno originário de uma função essencial no mundo da produção econômica, cria para si, ao mesmo tempo, de um modo orgânico, uma ou mais camadas de intelectuais que lhe dão homogeneidade e consciência da própria função, não apenas no campo econômico, mas também no social e no político: e o empresário capitalista cria consigo o técnico da indústria, o cientista da economia política, o organizador de uma nova cultura e de um novo direito. (GRAMSCI, 1995a, p. 3-4).

A autonomia dos intelectuais orgânicos frente às classes que eles representam elevaos acima do estágio econômico-corporativo. Ao se desprenderem da classe dominante, os intelectuais orgânicos unem-se mais intimamente a ela para constituírem uma verdadeira superestrutura "e não apenas um elemento inorgânico e indistinto da estrutura-corporação" (GRAMSCI, 1991, p. 424). A relação do intelectual com o mundo se dá num processo pelo qual os momentos se articulam, numa relação mediatizada e graduada. A relação entre os intelectuais e o mundo da produção não é imediata, como é o caso nos grupos sociais fundamentais, "mas é sim 'mediatizada', em diversos graus, por todo o contexto social, pelo conjunto das superestruturas, do qual os intelectuais são precisamente os funcionários" (GRAMSCI, 1995a, p. 10).

Como recorda Portelli (1998), o caráter mediato do vínculo orgânico manifesta-se, sobretudo, por causa do choque com as camadas dos intelectuais do antigo bloco histórico suplantado pela classe dominante que representam. Os intelectuais do antigo bloco histórico são denominados tradicionais formados pelo agrupamento das "diversas camadas de intelectuais que existiam antes do surgimento da nova classe fundamental" (PORTELLI, 1998, p. 90). Trata-se do processo da eliminação coercitiva ou legal do elemento que soldava o antigo bloco hegemônico. A partir dessa noção mais ampla de intelectual passamos a analisar a questão da produção da ciência no pensamento de Gramsci. Conforme o autor, a classe detentora do capital monopoliza a cultura, a ciência e a arte. A ciência torna-se, portanto, meio de apropriação e expropriação econômica e cultural. Os intelectuais apropriando-se do conhecimento e detendo os instrumentais para produzi-lo e transmiti-lo contribuem para explicar, conservar ou transformar a sociedade na qual estão inseridos. A universidade, na sua correlação com os meios de produção material, reproduz e corresponde às necessidades sociais conforme as influências dos grupos organizados defensores dos interesses de classes. Desta maneira, evitaríamos criar indivíduos que exploram ou vivem do trabalho dos outros ao que Gramsci chamaria de mamíferos de luxo.

O papel da escola é estratégico nesse processo. Como enuncia Saviani (1991), a partir do advento das novas relações de produção capitalista, a escola tornou-se o principal centro de educação. A escola foi erigida na forma principal e dominante da educação. Em suma, "por razões econômicas, sociais, políticas e ideológicas, a tese básica do liberalismo em matéria de ensino afirma o primado da instrução pública e, em consequência, o dever indeclinável do estado de organizar, manter e mesmo de impor a educação a toda a população" (SAVIANI, 1991, p. 94- 95).

A educação, ainda que muitas vezes tivesse seu caráter de investimento lucrativo negado, tornou-se sempre um fator de destaque nas preocupações empresarias. Desde as preocupações de Smith com uma instrução mitigada aos trabalhadores, passando pela 
proposta de uma educação mais diversificada e constante de Condorcet (2014), chegando aos princípios da educação liberal contemporânea de adequação da mão de obra a partir da especialização e da disciplina, inerentes à proposta taylorista, tem-se destacado o papel do Estado como responsável pela educação básica, embora devessem prevalecer as escolas da livre iniciativa com objetivos idênticos, isto é, voltados para a preparação do trabalhador em vista de aumentar a sua eficiência e a adaptabilidade em obediência aos imperativos da produção, ainda que as escolas particulares estivessem voltadas para o outro lado, o dos futuros dirigentes das linhas de produção.

Diante de tudo isso, as políticas de formação docente passam a crescer de uma forma assustadora na América Latina. Não com o sentido de politizar o docente, mas sim de alienálo diante das mazelas do mercado. A prática docente passa a ser valorizada em detrimento da teoria na formação dos professores. A técnica vale mais do que a fundamentação teórica sólida e consistente. A inversão de valores passa a ser a realidade histórica almejada.

\title{
APROXIMAÇõES CONCLUSIVAS
}

\begin{abstract}
"Pode-se ter um termo de comparação na esfera da técnica-industrial: a industrialização de um país mede sua capacidade de construir máquinas que construam máquinas, e na fabricação de instrumentos cada vez mais precisos para construir máquinas e instrumentos que fabriquem máquinas. O país que possuir a melhor capacitação para construir instrumentos para laboratórios de cientistas e para construir instrumentos que fabriquem esses instrumentos, esse país pode ser considerado o mais complexo no campo técnico-industrial, o mais civilizado, do mesmo modo ocorre na preparação dos intelectuais e nas escolas destinadas a tal preparação". (GRAMSCI, 1995a, p. 09).
\end{abstract}

A tarefa docente na contemporaneidade se mostra complexa. A escola, principalmente os educadores e as educadoras, vê-se comumente perante uma realidade para qual não está preparada, considerando a vertiginosa rapidez com que se processam as mudanças na sociedade da informação e das inovações tecnológicas.

A formação inicial já não dá conta de todas as demandas que se espera do professor, fazendo com que a formação continuada seja uma necessidade vital à sobrevivência da escola. Neste sentido, as políticas públicas têm desempenhado um papel importante, pois possibilitam que municípios e estados, juntamente com a União, desenvolvam projetos neste sentido. Os relatos mostram que as experiências têm sido muito positivas.

Ainda assim, uma formação inicial sólida permite que o docente tenha consciência da necessidade de sua profissionalidade, do ser e do estar na docência, ofício que requer não somente um profundo conhecimento da área específica e técnica, mas também um conjunto de competências que vão além da mera transmissão de conhecimentos. Políticas como o REUNI, a UAB e o Pró-Licenciatura, o PARFOR e o PIBID, além de iniciativas locais de alguns Estados da Federação, auxiliam no alcance do objetivo de qualificar nossos professores para que tenhamos uma educação de qualidade. Que qualidade é essa? Voltada para mercado capitalista ou para o mundo do trabalho? Alienação ou formação da consciência é o foco?

O trabalho colaborativo apresenta-se como uma alternativa importante para viabilizar a formação da profissionalidade docente, possibilitando ao educador sua autovalorização, 
bem como de parte da sociedade e das autoridades. No viés da formação continuada por meio do trabalho colaborativo, Damiani et al. (2009) supõem como fatores que podem influenciar fortemente esta prática: a qualidade das trocas que ocorrem e o ambiente no qual acontecem, que deverá ser propício, estimulando o diálogo e a participação de todos. Como princípios sobre os quais deverá assentar-se o trabalho colaborativo entre o grupo, deveremos estabelecer-se um clima de respeito mútuo e de valorização como pessoas. Além disso, as experiências e as dificuldades socializadas adquirem um sentido de aprendizagem, auxiliando a resolução de problemas e na tomada de decisões, tanto no campo individual, quanto no coletivo.

Ao estudarmos, por outro lado, a prática do intelectual como inserido no contexto histórico mais amplo, novos elementos apresentam-se. Entre estes, destacam-se as opções e as posições do intelectual frente à correlação de forças políticas. Neste âmbito, interessa a análise das concepções ideológicas inerentes às práticas dos intelectuais. Ideológico no sentido de visão de mundo, de sociedade e, sobretudo, do papel da ciência. Aqui se exige um posicionamento político do professor. Esse posicionamento pode ser tácito ou confesso. Nisso reside o aspecto ideológico, uma vez que estamos no campo da persuasão. Para Gramsci, as lutas sociais e políticas nas sociedades atuais se dão menos contra o Estado do que no Estado. Este se apresenta como instância mediadora de interesses de classes, em vez de um mero representante da classe dominante. Nele, portanto, os antagonismos se manifestam. $\mathrm{O}$ papel do intelectual orgânico é o de organizar, conduzir e persuadir as massas, produzindo consensos. Ao ampliar o Estado, ele amplia, também, o papel do intelectual.

Gramsci fala de várias formas de se obter a vontade coletiva. Ela pode surgir extrinsecamente, quando um herói ou homem representativo a propõe, sendo, porém, instável: "compondo-se e decompondo-se continuamente" (GRAMSCI, 1991, p. 169). Ela também pode surgir a partir do fetichismo, num processo em que se atribui a toda organização um poder operante que de fato não possui. Por fim, existe a real expressão do coletivo que "é constituído de indivíduos singulares, os quais formam o organismo na medida em que se entregam e aceitam ativamente uma hierarquia e uma direção determinadas" (GRAMSCI, 1991, p. 177). Essa consciência coletiva se forma conforme um consenso ativo e direto, com a participação dos indivíduos, com o atrito entre eles, mesmo que isso provoque uma aparência de desorganização e tumulto. Neste caso o organismo não é estranho aos indivíduos.

No entanto, devemos lembrar que o embate hegemônico em Gramsci supõe que a verdadeira práxis "não é o instrumento de governos ou de grupos dominantes para obter o consentimento e exercer a hegemonia sobre as classes subalternas" (GRAMSCI, 1995b, p. 270). Afirmamos, ao contrário, que a práxis é expressão das classes subalternas que querem educar a si mesmas na arte do governo e que tem interesse em conhecer todas as verdades inclusive as desagradáveis - e evitar enganos.

As noções gramscianas são importantes para uma análise histórica da atividade acadêmica. Elas nos permitem pensar o papel do intelectual, em suas várias modalidades. É possível contrapor o intelectual comprometido com a transformação da sociedade capitalista, rumo a uma organização econômica mais justa, aos interesses do capital, portanto direcionados pelos 
rumos do mercado, movidos pela lógica do lucro. Com a hegemonia maciça do liberalismo, esse enfoque pode parecer anacrônico.

\section{REFERÊNCIAS}

ABDALLA, M. F. B. Formação e desenvolvimento profissional do professor: o aprender da profissão (um estudo em escola pública). Augusto Guzzo Revista Acadêmica, n. 3, p.15-30, 2001. DOI: http://dx.doi. org/10.22287/ag.v0i3.89.

ALMEIDA, M. L. P. Universidade Pública e Iniciativa Privada. Campinas: Editora Alínea, 2002.

BAUMAN, Z. Modernidade líquida. Rio de Janeiro: Zahar, 2001.

BOLÍVAR, A. Retos actuales del Área de Didáctica y Organización Escolar en el ámbito universitario: experiencias, interrogantes e incertidumbres didáctica y currículum. Reunión Área Didáctica y Organización Escolar. Valencia, 15-16 mayo 2003. Disponível em: http://dialnet.unirioja.es/servlet/ articulo?codigo $=2557772$. Acesso em 20.11.2015.

BRASIL. Ministério da Educação. Conselho Nacional de Educação. Resolução $\mathbf{N}^{\mathbf{0}} \mathbf{2}$, de $\mathbf{1}^{\mathbf{0}}$ de julho de 2015. Define as Diretrizes Curriculares Nacionais para a formação inicial em nível superior (cursos de licenciatura, cursos de formação pedagógica para graduados e cursos de segunda licenciatura) e para a formação continuada. Brasília, 01 de julho de 2015. Disponível em: http://portal.mec.gov.br/index. php?option=com_docman\&view=download\&alias=17719-res-cne-cp-002-03072015\&category_slug=julho2015-pdf\&Itemid=30192. Acesso em: 02.12.2015.

BRASIL. Presidência da República. Lei n. ${ }^{0}$ 9.394, de 20 de dezembro de 1996. Estabelece as diretrizes e bases da educação nacional. Brasília: 20 de dezembro de 1996. Disponível em: <www.planalto.gov.br/ ccivil_03/LEIS/19394.htm>. Acesso em: 20.11.2015.

CONDORCET, N. et al. Essai sur l'application de l'analyse à la probabilité des décisions rendues à la pluralité des voix. England: Cambridge University Press, 2014.

DAMIANI, M. F.; PORTO, T. M. E.; SCHLEMMER, E. (Orgs.) Trabalho colaborativo / cooperativo em educação: uma possibilidade para ensinar e aprender. São Leopoldo: Oikos; Brasília: Liber Livro, 2009.

DEVÉS, E. V. El pensamiento latinoamericano en el siglo XX. Tomo II. Desde la CEPAL al neoliberalismo (1950-1990). Santiago: Editorial Biblos. Centro de Investigaciones Diego Barros Arana, 2003.

DOURADO, L. F. A interiorização do ensino superior e a privatização do público. Goiânia: Ed. da UFG, 2001.

DOZOL, M. S. Concepção histórico-crítica da educação: duas leituras. Revista Perspectiva. Florianópolis: UFSC/CED, NUP, n. 21, 1994, p. 105-118.

DUARTE, N. Vigotski e o "aprender a aprender": crítica às apropriações neoliberais e pós-modernas da teoria vigotskiana/Newton Duarte. 2. ed. rev. e ampl. Campinas, SP: Autores Associados, 2001.

FRIGOTTO, G. Os delírios da razão: crise do capital e metamorfose conceitual no campo educacional. In: GENTILLI, P. Pedagogia da exclusão. São Paulo: Vozes, 1995. p. 77-107.

GATTI, B. A.; BARRETO, E. S. S.; ANDRÉ, M. E. D. A. Políticas Docentes no Brasil. Brasília: Unesco, 2011.

GRAMSCI, A. Obras escolhidas. Volume I. Tradução de Manuel Cruz. Instituto Gramsci. Lisboa: Editorial Estampa, 1974. 
GRAMSCI, A. Cadernos do cárcere. v. 3 - Maquiavel: notas sobre o estado e a política. Rio de Janeiro: Civilização Brasileira, 2011.

GRAMSCI, A. Os intelectuais e a organização da cultura. 9. ed. R.J.: Editora Civilização Brasileira, 1995 a.

GRAMSCI, A. Concepção dialética da história. R. J.: Ed. Civilização Brasileira, 1995b.

GRAMSCI, A. Maquiavel, a Política e o Estado Moderno. 8. ed. R.J.: Ed. Civilização Brasileira, 1991.

GRAMSCI, A. Quaderni del carcere, Torino: Enaldii Editore, 1975, vol. I e II.

IMBERNÓN, Francisco. Formação docente e profissional: formar-se para a mudança e a incerteza. São Paulo: Cortez, 2001.

JUNG, H. S.; SUDBRACK, E. M. Pátria educadora ou Pátria panóptica? Revista Cocar, v. 10, n. 19, p. 265-286, 2016.

JUNIOR, R. L. Hegemonia e contra-hegemonia na construção de políticas de Esporte e Lazer: A experiência do Consórcio Brasília. Tese (Doutorado em Educação Física). 205f. Campinas: Unicamp, 2013.

KESLEY, P. Bolsistas se mobilizam nas redes sociais contra cortes no principal programa federal de formação de professores. Notícia no site da Organização sem fins lucrativos Todos pela educação, de 04 de dezembro de 2015. Disponível em: http://www.todospelaeducacao.org.br/reportagens-tpe/36265/ ficapibid/?pag=ultima. Acesso em: 13.01.2017.

KOSIK, K. Dialética do Concreto. 4. ed. Rio de Janeiro: Paz e Terra, 1986.

LIBÂNEO, J. C. Os conteúdos escolares e sua dimensão crítico-social. Revista da ANDE, n. 11, 1986.

LÜCK, H. Gestão Educacional: uma questão paradigmática. 8. ed. Petrópolis, RJ: Vozes, 2011.

MISOCZKY, M. C. A.; MORAES, J.; FLORES, R. K. Bloch, Gramsci e Paulo Freire: referências fundamentais para os atos da denúncia e do anúncio. Caderno EBAPE. BR, v. 7, n. 3, p. 448-471, 2009. DOI: http://dx.doi.org/10.1590/S1679-39512009000300005.

MOLES, A. As ciências do impreciso. R.J. Ed. Civilização brasileira. 1996

NÓVOA, A. Professores, Imagens do futuro presente. Lisboa: Educa, 2009, 41 p.

PICADO, L. Ser professor: do mal-estar para o bem-estar docente. Portal dos Psicólogos. 25.04.2009. Disponível em: www.psicologia.com.pt. Acesso em: 11.11.2015.

PORTELLI, H. Gramsci y el bloque histórico. Siglo XXI, 1998.

ROCHA, L. M. F. A concepção de formação continuada nos programas da união e repercussões no âmbito municipal. Dissertação (Mestrado em Educação). 142f. Universidade Federal da Grande Dourados. Dourados, MS: UFGD, 2010.

SAVIANI, D. A História da educação e sua importância para a formação de professores. In: Conferência de abertura do I Seminário de História da Educação Brasileira e Catarinense. UFFS. 2013.

SAVIANI, D. Pedagogia histórico-crítica: primeiras aproximações. $11^{\mathrm{a}}$ ed. rev. Campinas, SP: Autores Associados, 2011.

SAVIANI, D. Formação de professores: aspectos históricos e teóricos do problema no contexto brasileiro. Revista Brasileira de Educação, v. 14 n. 40 jan. / abr. 2009.

SAVIANI, D. Escola e Democracia. Edição Comemorativa. Campinas: Autores Associados, 2008. 
SCHÖN, D. Formar professores como profissionais reflexivos. In: NÓVOA, A. (Org.) Os Professores e sua formação. Lisboa: Dom Quixote, 1992. p.77-92.

TORRES, L. M. A contra-hegemonia na formação de educadores do campo: uma análise sobre o curso de pedagogia da terra. Tese (Doutorado em Educação). 171f. Universidade Federal de Sergipe, Núcleo de Pós-Graduação em Educação. São Cristóvão, Sergipe. 2012.

Artigo recebido em: 28/02/2017

Aprovado em: 25/04/2017

\section{CONTATO PARA CORRESPONDÊNCIA:}

Hildegard Susana Jung. E-mail: hildegardsjung@gmail.com

NOTAS

1 Art. 12. Os estabelecimentos de ensino, respeitadas as normas comuns e as do seu sistema de ensino, terão a incumbência de: I - elaborar e executar sua proposta pedagógica; II - administrar seu pessoal e seus recursos materiais e financeiros; III - assegurar o cumprimento dos dias letivos e horas-aula estabelecidas; IV - velar pelo cumprimento do plano de trabalho de cada docente; $\mathrm{V}$ - prover meios para a recuperação dos alunos de menor rendimento; VI - articular-se com as famílias e a comunidade, criando processos de integração da sociedade com a escola; VII - informar os pais e responsáveis sobre a frequência e o rendimento dos alunos, bem como sobre a execução de sua proposta pedagógica. VII - informar pai e mãe, conviventes ou não com seus filhos, e, se for o caso, os responsáveis legais, sobre a frequência e rendimento dos alunos, bem como sobre a execução da proposta pedagógica da escola; (Redação dada pela Lei no 12.013, de 2009) VIII - notificar ao Conselho Tutelar do Município, ao juiz competente da Comarca e ao respectivo representante do Ministério Público a relação dos alunos que apresentem quantidade de faltas acima de cinquenta por cento do percentual permitido em lei (Incluído pela Lei no 10.287, de 2001). Disponível em: http://www.jusbrasil. com.br/topicos/11694640/artigo-12-da-lei-n-9394-de-20-de-dezembro-de 1996. Acesso em: 14.11.2015.

2 Tradução nossa. 